\title{
CORPORATE SECURITY IN TOURISM: THE EXAMPLE OF SLOVENIA
}

\author{
SEBASTJAN REPNIK1, GABRIELA ANTOŠOVÁ2 \\ ${ }^{1}$ Grm Novo mesto - Biotechnology and Tourism Centre, Slovenia \\ ${ }^{2}$ Czech Technical University, Masaryk Institute of Advanced Studies, Czech Republic
}

\author{
Mailing address: Gabriela Antošová, Masaryk Institute of Advanced Studies, Czech Technical University, Kolejní 2637, \\ Prague 6, Czech Republic, e-mail: gabriela.antosova@cvut.cz
}

\begin{abstract}
Introduction. Tourism is part of the global security space and is the largest global industry with the highest levels of annual growth. In recent years, the issue of security has begun to significantly impact the development of tourism. This requires answers regarding the satisfaction of tourists from security, cultural, economic and sociological perspectives. Material and Methods. Our research problem is aimed at corporate security in health resorts (one of the conditions for establishing a health resort is e.g. the surrounding environment, natural mineral water), which differs from the security present in hotels or other tourist facilities. In order to achieve the purpose of this study, we developed a new theoretical model of corporate security in health resort tourism where we applied both a qualitative and quantitative paradigm in this research. In the qualitative part of this study, we collected data using the methods of document analysis and interviews and processed it in the software Atlas.ti. In the quantitative part, we collected data using a survey questionnaire and analysed the results using the SPSS software Results. The study will contribute an original theoretical model of corporate security in Slovenian health resort tourism to the treasure trove of knowledge and it will be possible to theoretically verify it and apply it in health resorts. Conclusions. In this way, we opened up the theoretical and practical dimensions of poorly researched field of security in Slovenian health resorts and, in doing so, contribute to the better understanding and improving of models of corporate security in health resort tourism.
\end{abstract}

Key words: corporate security, health resorts, sustainable tourism, Slovenia

\section{Introduction}

Nowadays, tourism is part of the global security space and is the largest global industry with the highest levels of annual growth. According to the World Tourism Organization UNWTO [1], there were 1.4 billion tourist arrivals in 2019 (Index $2018 / 2017=106$ ). The connection between security and tourism has been present since the very beginning of modern tourism and the travel industry, which was established by Thomas Cook [2]. In 2019, this very travel agency went into compulsory liquidation.

We live in a revolutionary age of travel, transport and communications as a consequence of the high level of connectivity between them. By reducing the obstacles in travelling, tourism can develop and lead to many economic and societal benefits. The issue of its safety and security [3, 4, 5] also significantly affects its development. Due to unrest and uncertainty (e.g. terrorism), some countries are closing their borders and practising protectionism that results in additional obstacles in travelling [6]. In Europe, this is manifested in the closing of borders in certain countries (e.g. Hungary, Austria in 2018/19) due to refugees and migrants, which impedes the development of sustainable tourism in frontier tourist destinations.

Grizold and Bučar [7] have written about the security aspect of the negative phenomena of globalisation processes (e.g. organised crime, terrorism, refugees, etc.), which requires answers to the security, cultural, economic and sociological satisfaction of tourists. This can all be achieved by establishing corporate security. Due to the global significance and scope of sustainable tourism as an industry [8], the security issues and concerns do not only affect individuals and their decisions to travel, but also affect the economic and political stability of entire regions or even the entire world [9]. When a security threat emerges in a tourist destination or in its vicinity, this usually results in a drop in tourist arrival numbers in the wider area affected as well as in local areas. The tourist potential security could be measured also in consequence of cooperation in the European Union with "unifying" criteria within the strategic partnership. Authors (such as Wilks and Page [10]) for the most part agree that attacks on the US after 11 September 2001 changed our perception of security in international sustainable tourism forever.

Security as a virtue is gaining in significance, which consequently means that the future of the tourism industry is increasingly dependent on the security factor [11]. The bottom line is tourists choose safe destinations to travel to. Čavlek [12] claims that tourists today have a wide range of options to choose from regarding where to spend their holidays and where to travel to, which makes it easy to simply replace a potentially dangerous tourist destination with a similar or completely different safer destination. Hreščak [13] points out that in recent times, security is becoming one of the key criteria used by tourists to decide whether they will visit a country or not. Their perception of security in a particular tourist destination can be a consequence of personal experiences or information obtained from a variety of media $[14,15,16,17]$.

\section{Material and Methods}

This research problem is aimed at corporate security in health resorts, which differs from the security present in hotels or other tourist facilities. Corporate security in health resorts is an area that has not yet been studied; therefore, this study is of an exploratory nature and will allow us to gain valuable insight in the case of Slovenia into the concept of corporate security, interpretation and practices of guests, employees and managerial staff in health resorts. The research problem was tied to three areas - tourism, management and criminology. No such link has yet been made in the literature. Researching the concept of corporate security itself from the perspective of factors that affect corporate security and how health resort guests perceive 
them, and gaining in-depth insight into the interpretation and practices of those who are most knowledgeable about this issue represented a substantial challenge and was the central focus of study.

\section{Purpose, objectives and research questions}

The purpose of this study was to develop a new theoretical model of corporate security in health resort tourism on the basis of a review of contemporary Slovenian and foreign literature, resources and empirical studies, which will be possible to verify at a later point from the perspective of reducing risk in Slovenian tourism. As a result, managers in tourism will be able to reduce the risk. We studied the processes that affected the effective management of risk in corporate security [18]. Accordingly, we analysed the factors that affect decision-making about corporate security in health resorts. The study will therefore fill an empirical gap in the theoretical understanding of the concept of corporate security in health resort tourism in Slovenia and the interpretation of practices of study respondents. With the help of the study findings, we created a theoretical model for managing such risk in the field of corporate security in health resort tourism.

The gained insight and knowledge about corporate security in Slovenia health resort tourism will contribute to the development of theoretical knowledge and, with this, to science, as well as recommendations on how to provide suitable security in Slovenian health resort tourism.

We set the following objectives:

1) To study, analyse, compare, review and critically assess the contemporary Slovenian and foreign literature, as well as sources from the field of corporate security in health resort tourism. To find and study the studies and articles from this field that are aimed at health resort corporate security and analyse the documents that are publicly available.

2) To obtain an in-depth insight into the concept of corporate security in health resorts, as is held by the study participants.

3) To determine the factors of corporate security in health resort tourism. We studied:

a) The factors of corporate security that are perceived by guests in health resorts,

b) The factors that, in the opinion of decision-makers, affect the perception of corporate security in health resorts, and

c) The gaps in the perceptions of impact. On the basis of this we identified and studied the factors that affect decision-making in processes of managing corporate security in health resort tourism and

d) How the study participants interpret the security culture of organisations in the field of Slovenian health resorts.

4) To develop a new theoretical model of corporate security in health resort tourism and evaluate it.

5) Based on the development of a new theoretical model of corporate security in health resort tourism, to provide recommendations for further research and practice.

The study was designed as a case study and was divided into two parts, a qualitative and a quantitative part, and was aimed at studying corporate security in health resorts in Slovenia. We therefore assess that, using this case study, we can systematically analyse and present this case, as well as the individual groups of stakeholders. Simons [19] presented the following definition of a case study: "A case study is an in-depth exploration from multiple perspectives of the complexity and uniqueness of a particular project, policy, institution, programme or system in a real-life context".
A case study should not be approached simply as a method in and of itself, but should instead act as a framework that brings together a number of methods. Stake agrees, stating that a case study is not a methodological choice, but rather a selection of what is to be studied. A case can be studied analytically, holistically, hermeneutically, culturally and using a variety of methods [20]; however, in our case, we were concentrating on studying corporate security in health resorts [21]. A specific case can therefore be studied from different perspectives: both qualitative and quantitative ones. On this basis, we can also recommend carrying out a case study for the area of studying corporate security, as it is not possible to limit security to a specific area, but needs to be studied as a whole - social security within a wider social context.

The guiding principles of the study were the following research questions:

Research question 1 [RQ1]: How, if existing, is corporate security in health resort tourism defined from the perspective of security in existing publicly available documents, the literature and modern studies in comparison with the definition of corporate security as provided by the study participants?

Research question 2 [RQ2]: What type of corporate security model in Slovenia exists for the field of health resort tourism and how was it interpreted by the study participants?

Research question 3 [RQ3]: What significance is attributed to security in health resort tourism by the participants and how do they interpret the practices through their actions?

Research question 4 [RQ4]: How do the study participants interpret the security culture of organisations in Slovenian health resorts?

Research question 5 [RQ5]: In the opinion of the participants, what are the factors that impact the corporate security system in Slovenian health resorts?

In order to achieve the purpose of this study: to develop a new theoretical model of corporate security in health resort tourism, we applied both a qualitative and quantitative paradigm - triangulation.

\section{Qualitative paradigm}

In order to gain an in-depth extent of information, understanding and consideration of the individual stakeholders linked with the actual circumstances that affect corporate security, we used qualitative research based on [22] several scientific paradigms: interpretative paradigm, constructivism, symbolic interactionism and phenomenology. With the help of interviews, we thus sought to understand and interpret the views on the studied problem from the perspective of each person interviewed, which served as the research basis [23] of the interpretative paradigm. Corporate security, as a scientific field that has only recently begun to be studied, is also formed through beliefs - by participants attributing significance to specific phenomena and through interacting with society, which can also be studied by using a constructivist approach. Constructivists [24] believed in the existence of a reality that could be comprehended by attributing significance to phenomena and other things. Communication that the people interviewed experienced in work processes affected the way they attributed meaning to the things they come into contact with in everyday business processes, which Šadl [25] explains through symbolic interactionism in a way that a connected society as a whole can be understood and explained through the result of the means of communication between people. A supposedly harmless event in a health resort 
can be perceived by individuals in various ways as a consequence of the difference between the truth and the way it appears. The reason behind this is the different preconceptions held by an individual that perceives the situation through their own personal intuition. This area is studied by the science of phenomena, also known as phenomenology.

\section{Data collection methods and sample}

In the qualitative part of our study we used the following methods: document analysis and interviews.

Document analysis is a non-interfering unreactive technique of collecting data, since we analyse existing documents that exist independently of the research process and which can be analysed by the researcher without disturbing the material's author. An interview is a technique used to collect data through conversational communication; it is a conversation between two people, whereby one (the interviewer) asks questions and the other (the interviewee) answers these questions [26]. To collect the necessary data, we used the method of collecting primary data with the help of a semi-structured interview. For the qualitative analysis of texts and the processing of the collected data we used the Atlas.ti software and manual processing (Microsoft Excel), the latter was used primarily due to the smaller sample of interviewees studied. The population comprised Slovenian tourism companies that cover the field of natural health resorts. We chose Slovenian natural health resorts (SNHR) that are members of the economic interest association (EIA) which includes ten companies. We studied on the basis of which factors managers of these tourism companies decide on measures to reduce specific risks regarding corporate security in tourism. In these companies, we carried out semi-structured interviews with the people who are responsible for corporate security in tourism and are knowledgeable in this area. We performed interviews with people who cooperate with companies as external and internal associates. We personally contacted the participants over the telephone and arranged for the interviews. The external stakeholders we performed group interviews with were: chief firefighters in the region where the health resort was located and chiefs of police. Both cases represent purposive samples of the most knowledgeable informants. The purposive sample of health resorts was selected on the basis of business ties.

We analysed the obtained data using the following method: the content analysis method. We performed a data analysis (content analysis method) using the appropriate software for qualitative research (Atlas.ti and manual processing in Microsoft Excel), we clarified how the interviewees understand, perceive, evaluate corporate security in tourism. The qualitative analysis of collected data took place in several phases. The transcriptions of interviews and responses to the open-ended questions were made. We then divided the transcriptions to highlight important information. We adhered to the standards and principles of high-quality and ethical evaluation: e.g. voluntary participation in the study, protection of participant identities [27]. The findings obtained in this way were used to make a comparison with the known facts in the literature and, on the basis of this, we formed the final conclusions of the study and developed an improved system of corporate security for tourism, which will be theoretically presented to interested health resorts in Slovenia.

\section{Quantitative paradigm in research}

Considering the research area that also includes the guests' perception of corporate security, we applied a quantitative research paradigm or explanatory paradigm in part of our study, i.e. a paradigm where the researcher wishes to show the order of addressed phenomena that has its philosophical basis in positivism [28]. We therefore carried out a study among guests of Slovenian natural health resorts using an anonymous survey questionnaire in order to obtain an in-depth insight into the concept of corporate security in health resorts, as is held by the study participants. We studied the factors of corporate security that are perceived by guests in health resorts, and we identified gaps in the perceptions of impact. On the basis of this we identified and studied the factors that affect decision-making in the processes of handling corporate security in health resort tourism.

\section{Data collection methods and sample}

In the quantitative part of our study, we used the following methods: a survey questionnaire with set questions where the form of the responses was anticipated. We gathered survey data using a survey questionnaire that comprised questions prepared in advance, whereby the form of the responses is also anticipated [29]. In our case, these are close-ended questions on the topic of perception of guest security, with which we gained in-depth insight into how guests perceive corporate security in tourism. We carried out the survey by directly contacting the respondents. The survey questionnaires were anonymous, which is important when dealing with sensitive topics or when the respondent could feel vulnerable when communicating specific information. We used a Likert scale to rate the opinions regarding guest security. We also performed an analysis of internal documents (e.g. security standards, security records) in the health resorts that were being studied with regard to corporate security and that were willing to communicate such documents. The documents were used as support in studying the processes of corporate security in Slovenian tourism, since the purpose of the study was to obtain information about the elements, processes and procedures that ensure corporate security in Slovenian tourism.

We carried out the survey on Slovenian and foreign guests staying at one of the studied health resorts (7 SNHR took part); we surveyed 342 guests in total in the period from February 2018 to April 2018. The sample was an opportunity sample, which means that it included the guests of the chosen health resorts that were staying there at the time the study was carried out. It was not possible to generalise the survey results.

We analysed the obtained data with the help of descriptive statistics, factor analysis and regression analysis. We used the SPSS software for data collected with the survey questionnaire. To show the results of our studies, we also used different statistical indicators (descriptive statistics), such as the arithmetic mean, the Mann-Whitney test, frequency distributions of response where the independent variables are shown. In addition, we used a T-test to verify certain findings. Factor analysis is a model used to attempt to explain the interrelationships between a large number of variables with a smaller number of factors that represent the total dimensions [30]. A study of the connections between the variables with which we were attempting to identify a new set of variables (fewer that the measured variables), which represented what is shared by the observed variables [31]. In studying the complex phenomena, we must often consider many interdependent variables. Using regression analysis, we can study the interdependence of two or more common variables. With one dependent and one independent variable we get basic regression. When multiple factors or variables affect the value of one dependent variable, we get multiple regression. If a dependence exists between the observed varia- 
bles, it is possible to devise a regression equation. The reliability of the calculated regression equation was determined using an F-test, while the reliability of its (partial) regression coefficients was determined using a T-test [32].

\section{Results}

The analysis was divided into three parts: the analysis of quantitative data that included a factor analysis and survey of the guests, as well as a qualitative data analysis.

\section{Quantitative data analysis - factor analysis}

We combined 100 opinions into the following 6 sections that constituted the factors: the security section (SS) contains 10 opinions, the security in tourist destinations (STD) contained 5 opinions, the personal security (PS) contained 24 opinions, the general hotel security contained 42 opinions, the hotel room security (HRS) contained 8 opinions and the wellness security (WS) contained 8 opinions. Three opinions were not classified into any of the sections. The sections were made as factor analysis was not possible on the basis of 100 opinions since certain opinions were negatively correlated to each other. With the sections, we carried out a factor analysis from which we then obtained the combined dimensions of the factors. We performed a Kaiser-Meyer-Olkin (KMO) Test and a Bartlett Test on each individual section of opinions. The KMO value must be at least 0.50 to enable a factor analysis or main component analysis.

\section{Quantitative data analysis - surveying guests}

For the performance of further analysis and an interpretation of the survey questionnaire results, we carried out a distribution normality test using the Shapiro-Wilk and Kolmogorov-Smirnov tests. Then, depending on the result, we selected non-parametric statistical tests for further analysis. For the section of questions about "Security in Health Resorts" and the section about "Guest Habits", we performed a questionnaire reliability test using Cronbach's alpha. The reliability value for the first set is 0.878 , which means good reliability, for the second set 0.673 , which means acceptable reliability. Using the Mann-Whitney U test and the Kruskal-Wallis test we verified the differences in opinions depending on the country of the respondent (from Slovenia 283, Italy 21, Austria 7, Croatia 7, other EU 12 and other countries 12 ) and their age (18-28, 29-39, 40-50, 51-61, 62 and more). The values (Kruskal-Wallis test - the country of the respondent) of $\mathrm{p}$ (level of importance) are below 0.05 and thus statistically significant in almost all statements except for five of them, where the values of $p$ are greater than 0.05 for example at the statement: "Safety provided by the police and the army at the location is important for the spa" $(\mathrm{p}=0.451)$. In all claims (Kruskal-Wallis test - the age of the respondent), respondents have the highest average rank in the age group over 62 years (in the order of claims 190.75; 189.75; 188.04; 184.14 and 191.94), which means that the most 156 agree with the above statements. The results are expected, because with aging we become more careful and sensitive to areas or factors that affect our security. Using the Mann-Whitney $U$ test we verified the differences in opinions depending on the respondents' gender. For all statements that are statistically significantly different according to gender, women as respondents have, on average, a higher grade point average, which means a higher degree of agreement, but this does not apply to all questions in the questionnaire. Using the Kruskal-Wallis test we verified whether the differences in opinions depended on the average length of stay (1-3 days, 4-6 days, 7-10 days, 11-14 days, 15 and more) and the number of visits to the health resort (first time, second time, third time, fourth time and more). The values (the average length of stay) of p are below 0.05 and thus statistically significant in the statement "Safety provided by the police and the army on the site is important for the health resort" $(\mathrm{p}=0.041)$ and the statement "It is important for the health resort to respect culture and safety at the tourist destination" ( $p=0.003)$. The values (the number of visits to the health resort) of p (level of importance) are below 0.05 and thus statistically significant in three statements: "Institutional/organizational security is important for health resorts" ( $p=0.026)$, "Health safety and validity of tourist visas of guests at a tourist destination are important for a health resort" ( $p=0.015)$ and "Cyber and information security in the spa is important for guests" $(\mathrm{p}=0.012)$.

\section{Qualitative data analysis - interviews}

We analysed the obtained data using the content analysis method, as described by Easterby-Smith, Thorpe, and Lowe [33], and used the Atlas.si software and also performed a manual analysis.

We studied how interviewees understand, perceive and evaluate corporate security in tourism. The qualitative analysis of collected data took place in several phases. We first performed a transcription of the interviews. We then divided the transcriptions to highlight important information. The findings obtained in this way were used to make a comparison with the known facts in the literature and, on the basis of this, we formed the final conclusions of the study and developed an improved system of corporate security for tourism, which will be theoretically presented to health resorts in Slovenia. We also performed an analysis of the internal documents (e.g. security standards, security records) in the health resorts that were being studied with regard to corporate security and who were willing to communicate such documents. We also performed a manual data analysis by organising the collected semi-structured interviews in an Excel spreadsheet, then comparing and arranging it by content into the following categories that we defined on the basis of the questions in the semi-structured interview: the importance of security, the importance of corporate security, the importance of security in SNHR, threats to the security of guests/employees in your health resort. We further divided each category into subcategories. We defined the following subcategories for the importance of security: security at home - SNHR and elsewhere in the world, security trends in modern tourism, interventions and the perception of security in SNHR. For the category of importance of corporate security: corporate security in practice, investing in corporate security, and involvement of the police/firefighters. For the category of importance of security in SNHR: the importance of security culture, security culture in practice and the values of security culture. For the category of threats to the security of guests/employees in your health resort: threats to the security of guests/employees, the typical behaviour of guests/employees, and the different demands of guests depending on their country. We added statements from interviewees to each category.

On the basis of refining and combining the meaning of words, we selected the words that defined the objectives of the qualitative part of the study. Using the selected words, we allocated parameters or codes to each individual part [34]. We first imported three documents into the Atlas.ti program with semi-structured interviews divided depending on the professional status of the interviewee: Security experts in a SNHR, chiefs of firefighting associations and chiefs of police stations. All the semi-structured interviews were categorised in all four 
content categories that had already been listed. We entered the statements individually according to the professional status of the interviewees.

\section{Conclusions and discussion}

The concept of security is unifiedly understood by the study participants; however, security at home and around the world is understood in different ways. The studied SNHR attempt to ensure a "subjective dimension of security" by ensuring an "objective dimension of security", i.e. using security cameras, observing the legislation governing fire safety, occupational safety, handling data safely (e.g. the GDPR), and in doing so, preserve the diversity that refers to, e.g. when we are friendly to guests, we give them a sense of security, which creates a sense of belonging and trust among employees, interactions between employees, a concern for fellow human beings. The health resorts included in our study possess an objective dimension of security and a subjective dimension of security; however, the way in which individuals perceive security differs. The main reason behind this is the cognitive-terminological dilemma, which is connected to the phenomenon of security. That security is a controversial concept was mentioned by W. B. Gallie in 1962 and Patman in 1999 [35] after the cold war. These researchers emphasised the contentiousness of this concept, as decisions about what security really is are based on subjective aspects and subjective dimensions of security due to, e.g. political definitions, morals and ideals of an individual. In his Metaphysics (book 4, Chapter 5, translated by Irwin and Fine [36]), Aristotle warned on the incongruence of truth, the appearance of truth and its perception. He highlighted the pointlessness of the statement that only what we perceive is real, as sooner or later something happens that we did not expect. Subjective dimension of security is connected to the Aristotle's point of view. He was using not just a mind as his teacher Plato but also feelings. In this sense, real security threats are not necessarily also perceived security threats, likewise the real security status of an individual, society, country does not necessarily match its perceived security. One of the possible consequences of this cognitive dilemma is that existing theoretical and empirical studies indicate a lack of a unified understanding of the concepts of security and threats to security. The concept of security would not even exist without threats to security. Similarly, it would not be possible to identify something as light or large without understanding this in relation to dark and small. On the other hand, Mroz defines security as the absence of harmful threats, while Wolfers presents security in an objective sense (the objective dimension of security) as a measurement of the absence of threats obtained with values, which, in a subjective sense (in a subjective dimension of security) means the absence of a fear that these values will come under attack.

In view of the statements provided by various types of experts, no differences exist in the security threat to guests/employees. In view of the professional field, differences only exist in the treatment of cases of security accidents. A different protocol exists for chiefs of firefighting associations than for chiefs of police stations. We found there to be an absence of concrete statements of the standards used in SNHR to manage security, such as: ISO $28000: 2007$, adhering to the data protection standard ISO 27000 , the environmental security standard ISO 14000 , the occupational health and safety standard OHSAS 18001 and the system for the management of food safety ISO 22000 [37, $38,39,40]$; security and quality standards, the system for the management of food safety and the HACCP. ISO standards are the basis for managing risk and are one of the important tools used to successfully manage a company [41].

Using the survey questionnaire for guests of Slovenian natural health resorts, we achieved the goal that was to determine the factors of corporate security as perceived by guests, both Slovenian and foreign, of Slovenian natural health resorts, and to identify the gaps or deviations in the perception of impact among guests. On the basis of this we identified and studied the factors that affected decision-making in the processes of handling corporate security in health resort tourism. In our data analysis, we calculated various tests such as the Shapiro-Wilk and Kolmogorov-Smirnov. We also used non-parametric statistical tests. For the section of questions about security in health resorts and the section about guest habits, we performed a questionnaire reliability test using Cronbach's alpha. We further calculated certain statistical indicators such as the arithmetic mean and standard deviation. In continuation, we highlighted the most significant results of the survey questionnaire carried out among guests in SNHR, which show that the majority of respondents come from Slovenia and the fewest come from China and Russia. In the HDR report [42], human security is divided into two categories taking into account geographic location and economic development. It depends on whom we ask, whether French (European) or Japanese (Asian) or American, since a threat in France is perceived by a Japanese person as a threat to the whole of Europe, while a Parisian perceives it only as a threat to the part of Paris where the incident actually occurred. The most important aspect perceived by respondents was that they were not attacked by anyone and that they felt safe. The least important was to have a weapon on them, first aid, and having a police officer or firefighter as a friend. The results of the survey questionnaire can be linked to a statement by Bajpai [43], who asserted that this also referred to the protection of personal safety and individual freedom in the face of direct (e.g. violence, slavery) and indirect (e.g. shortages, underdevelopment, diseases, leaders) threats. An important approach to human security is also mentioned by other authors [44, 45, 46, 47, 48, 49], also Maslow, who in his hierarchy of needs ranks human security in the second place, immediately after physiological needs, and important world organisations HDR [42].

In the study, the majority of respondents among the surveyed guests of Slovenian natural health resorts were female, while the minority were male. We also performed the Mann-Whitney test as we wanted to verify whether the responses about security in health resorts differ significantly depending on gender. In all responses that differ significantly by gender, female respondents had a higher average range, meaning a greater degree of agreement, which was already confirmed in the HDR report [42], where it states that threats to personal security still occur that refer to violence and abuse of women, and a lack of the impact of violence and crime per person, primarily of more vulnerable women and children. The respondents agreed the least on the statement that security provided by the police and military at the location itself was important, and agreed the most on the statement that general personal security is important for health resorts. This is asserted by Bajpai [43], military security is relatively insignificant for corporate security in health resorts except for when the approaches, tactics and strategies of military security are incorporated into corporate security. Respondents agreed the most that organisational security in wellness is important for health resorts. This refers to the importance of the swimming pool as the largest facility for water that presents a variety of hazards (e.g. slipping, falling) and, with this, a threat to corporate security. In addition to the size of the swimming 
pool, its depth is also important, as is the use of suitable materials, the temperature of the water and air, water quality, and instructions that must be followed when by the pool. Great importance of changing rooms, showers, toilets, poolside bars, massage rooms, rooms for other forms of therapy and medical staff areas, which can be correlated to the highest level of respondent agreement that the health resort must ensure healthcare security in wellness.

The results showed that respondents value hotel security the most, while the placement of metal detectors (for weapons) at hotel entries and in other common areas is of the least importance. In spite of this, the hotel reception entrance as the most important location of first contact with guests, which has an important security function, which the fewest respondents agree with. The OECD also discusses hotel security, stating that hotel security is part of corporate security and arises from its guiding principles that serve as the framework for corporate management and must enable transparent and effective tourism markets that are consistent with the principles of the rule of law. The respondents most frequently expressed the opinion that general security at tourist destinations is the most important for a health resort guest, while the least important is security provided by the police and military at the location itself. Beirman (as cited in Rittichainuwat and Chakraborty [50]) found that the perception of security was an important factor in deciding on the tourist destination. The future of the tourism industry is increasingly dependent on the security factor. The bottom line is tourists choose safe destinations to travel to. Whereby their perception of security at a specific tourist destination depends on personal experience and transferred experience, e.g. of friends and in the media. The results of this study show that being informed and feeling good are of key importance to guests of health resorts, while respondents also attributed importance to the cybernetic and IT security of a health resort. Aspect particularly in a globally connected world regarding IT, where information can be transmitted from one side of the world to another in real time. Information about the escalation of a security threat can travel the world in real time, reaching the homes of potential tourists and deterring them from deciding to travel. Tourists generally have a short memory regarding the situation of tourist destination, as they will return there immediately after the direct threat goes away.

This part of the discussion and interpretation of the results of the survey questionnaire of guests at SNHR concludes with the performed analyses of guest enquiries, in addition to the hotel category, the security equipment of a hotel or health resort is also important. Security is ranked very high on the pyramid of values of a potential guest, which is why guests select a tourist destination and catering facility through a prism of security.

\section{References}

1. World Tourism Organization UNWTO (2019). International tourist arrivals reach 1.4 billion two years ahead of forecasts. Retrieved October 1, 2019, from: http://www2. unwto.org/press-release/2019-01-21/international-touristarrivals-reach-14-billion-two-years-ahead-forecasts

2. Kurež B. (2011). Modern security environment and tourism. Varstvoslovje 13(3), 330-347. [in Slovenian]

3. Zýka J., Drahotský I. (2019). Methodology for assessing the impact of workplace ergonomic factors on airport security screener's reliability and performance. Journal of Tourism and Services 10(18), 104-116. DOI: 10.29036/jots.v10il8.88.
4. Chehabeddine M., Tvaronavičienė M. (2020). Securing regional development. Insights into Regional Development 2(1), 430-442. DOI: 10.9770/IRD.2020.2.1(3).

5. Boustras G., Waring A. (2020). Towards a reconceptualization of safety and security, their interactions, and policy requirements in a 21st century context. Safety Science 132, 104942. DOI: $10.1016 /$ j.ssci.2020.104942.

6. World Economic Forum (2016). Security in travel: promoting seamless and secure travel through cross-border data sharing and collaboration. Retrieved March 25, 2019, from: https://www.weforum.org/reports

7. Grizold A., Bučar B. (2011). Challenges of modern security: from national and international to human security. Teorija in praksa 48(4), 827-851. [in Slovenian]

8. Barrero-Barrero D., Baquero-Valdés F. (2020). Sustainable development goals: A post-modern social contract for justice, development, and security. Revista Cientifica General Jose Maria Cordova 18(29), 113-137. DOI: 10.21830/19006586.562. [in Spanish]

9. Hall C.M., Timothy D.J., Duval D.T. (2003). Security and tourism: towards a new understanding? In C.M. Hall, D.J. Timothy, D.T. Duval (eds.), Safety and security in tourism (pp. 1-18). New York: The Haworth Press.

10. Wilks J., Page S.J. (2003). Managing tourist health and safety. In J. Wilks, S.J. Page (eds.), Managing Tourist Health and Safety (pp. 47-78). Oxford: Elsevier.

11. Meško G., Dobovšek B. (1999). Security and some sources of threat in tourism. In A. Anžič (ed.), Security and tourism (pp. 257-271). Portorož: Visoka šola za hotelirstvo in turizem - Turistica; Ljubljana: Visoka policijsko-varnostna šola. [in Slovenian]

12. Čavlek N. (2002). Tour operators and destination safety. Annals of Tourism Research 29(2), 478-496.

13. Hreščak, A. (2010). Slovenia is one of the safest tourist countries in Europe; but health workers in tourist resorts are overwhelmed. Diary. Retrieved June 6, 2019, from: http:// www.dnevnik.si/clanek/1042358808.

14. Pondelicek M., Silhankova V., Alfaro Valero A., Arias Gomez J. (2019). Perception of risk as a barrier in tourist destination development. A key study from Colombia. In V. Klimova, V. Zitek (eds.), 22nd International Colloquium on Regional Sciences (pp. 583-591). Masarykova Univ. DOI: 10.5817/ CZ.MUNI.P210-9268-2019-74.

15. Alola Andrew A., Eluwole Kayode K., Alola Uju V., Lasisi Taiwo T., Avci T. (2019). Environmental quality and energy import dynamics: The tourism perspective of the Coastline Mediterranean Countries (CMCs). Management of Environmental Quality: An International Journal 31(3), 665-682.

16. Huamin L., Xuejing Z. (2019). A study of factors of leisure tourism intention: Based on the Theory of Planned Behaviour. Transformations In Business \& Economics 18(1), 163182.

17. Antošová G., Lima Santos L., Stradová S. (2021) Perception of safety tourism in Colombia. In: A. Abreu, D. Liberato, E.A. González, J.C. Garcia Ojeda (eds), Advances in Tourism, Technology and Systems. ICOTTS 2020. Smart Innovation, Systems and Technologies (pp. 96-105). Singapore: Springer. DOI: 10.1007/978-981-33-4260-6_9.

18. Yorio P.L., Willmer D., Moore S.M. (2015). Health and safety management systems through a multilevel and strategic management perspective: Theoretical and empirical considerations. Safety Science 72, 221-228.

19. Simons H. (2009). Case study research in practice. London: SAGE. 
20. Stake R.E. (2005). Qualitative Case Studies. In N.K. Denzin, Y.S. Lincoln (eds.), The SAGE handbook of qualitative research (pp. 443-466). Thousand Oaks, CA: Sage.

21. Štefko R., Jenčová S. Vašaničová P. (2020). The Slovak spa industry and spa companies: Financial and economic situation. Journal of Tourism and Services 20(11), 28-43. DOI: 10.29036/jots.vlli20.137.

22. Vogrinc J. (2008). Qualitative research in the pedagogical field. Ljubljana: Univerza v Ljubljani, Pedagoška fakulteta. [in Slovenian]

23. Sagadin J. (2001). A review of qualitative empirical pedagogical research. Sodobna Pedagogika 2, 10-25. [in Slovenian]

24. Guba E.G., Lincoln Y.S. (2004). Competing paradigms in qualitative research: Theories and issues. In S.N. Hesse-Biber, P. Leavy (eds), Approaches to Qualitative Research (pp. 17-38). New York: Oxford University Press.

25. Šadl Z. (1992). Symbolic interactionism and the definition of the situation. Družboslovne Razprave 14, 73-81. [in Slovenian]

26. Holstein J.A., Gubrium J.F. (2004). Context: Working it up, down, and across. In C. Seale, G. Gobo, J.F. Gubrium, D. Silverman (eds.), Qualitative Research Practice (pp. 2-32). London: Sage.

27. Devjak, T. (2007). Rules and educational operation of the school. Ljubljana: Pedagoška fakulteta. [in Slovenian]

28. Mautner T. (1996). A dictionary of philosophy. London: Blackwell.

29. Bregar L., Ograjenšek I., Bavdaž M. (2005). Research methods for economists: selected topics. Ljubljana: Ekonomska fakulteta. [in Slovenian]

30. Mardia K.V., Kent J.T., Bibby J.M. (2003). Multivariate analysis. Amsterdam: Academic Press.

31. Ferligoj A. (2001). Factor analysis. Retrieved October 1, 2019, from: https://studentski.net/gradivo/upr_fmg_mnl_ rvm_sno_kvantitativne_metode_faktorska_analiza_predavanja_01_predstavitev. [in Slovenian]

32. Kodrič B., Strašek R. (2008). Research methodology in the social sciences. Basics of sampling and statistical reasoning: lecture notes. Koper: Fakulteta za Management. [in Slovenian]

33. Easterby-Smith M., Thorpe R., Love A. (2005). Research in management. Koper: Fakulteta za Management. [in Slovenian]

34. Kordeš U., Smrdu M. (2015). The basics of qualitative research. Retrieved October 1, 2019, from: http://www.hippocampus.si/ISBN/978-961-6963-98-5.pdf. [in Slovenian]

35. Patman R. (1999). Introduction: Security in a Post-Cold War Context. In R. Patman (ed.), Security in a Post-Cold War World (pp. 3-29). London: Macmillan Press.

36. Irwin T., Fine G. (1995). Aristotle: Selections. Indianapolis: Hackett Publishing Company.

37. Erjavec A. (2010). Information security in accordance with the ISO/IEC 27000 series of standards as an integral part of an integrated security system. Retrieved March 10, 2019, from: http://sciget.com/Predogled/2297/7fl29adcb7288d5f8e022641145654d44ba98.

38. Gostič Š. (2012). Ensuring corporate security through the ISO 28000: 2007 standard of the security management system. Korporativna Varnost 2, 24-27.

39. Hiti T. (2011). The decision model for the introduction of a security information and event management system. Master thesis. Ljubljana: Univerza v Ljubljani, Fakulteta za Računalništvo in Informatiko. [in Slovenian]
40. Vršec M. (2006). Establishing comprehensive protection as a preventive factor in companies. In A. Dvoršek, L. Selinšek (eds), Criminal attacks on the property of economic operators (pp. 83-101). Maribor: FPVV.

41. Dular D. (2017). Business continuity is becoming an important part of international corporations. Korporativna varnost 13, 20-23.

42. United Nations Development Programme (1994). Human Development Report (HDR). New York, Oxford: Oxford University Press.

43. Bajpai K. (2000). Human Security: Concept and Measurement. New Delhi: Kroc Institute.

44. Lincoln Ch.C. (1995). Human security: Concepts and approaches. In M. Tatsuro, C.Ch. Lincoln (eds), Common security in Asia New Concepts of Human Security (p. 139). Tokyo: Tokai University Press.

45. Haq M. (1995). Reflections on Human Development. New York: Oxford University Press.

46. Møller B. (2000). National, societal and human security A general discussion with a case study from the Balkans. In UNESCO - Division of Human Rights, Democracy, Peace and Tolerance, Social and Human Sciences Sector (ed.), What Agenda for Human Security in the Twenty-first Century? First International Meeting of Directors of Peace Research and Training Institutions (pp. 41-60). Paris: UNESCO.

47. Moussa G. (2001). Challenges to human security in the Middle East. In UNESCO - Division of Human Rights, Democracy, Peace and Tolerance, Social and Human Sciences Sector (ed.), What Agenda for Human Security in the Twenty-first Century? First International Meeting of Directors of Peace Research and Training Institutions (pp. 37-52). Paris: UNESCO.

48. Nef J. (1999). Human Security and mutual vulnerability the Global political Economy of Development and Underdevelopment. Ottawa: International Development Research Centre.

49. Suhrke A. (1999). Human security and the interests of states. Security Dialogue 30(3), 265-276. DOI: 10.1177/0967010699030003002.

50. Rittichainuwat B.N., Chakraborty G. (2009). Perceived travel risk regarding terrorism and disease: the case of Thailand. Tourism Management 30, 410-418.

Submitted: May 14, 2021

Accepted: August 20, 2021 